Louisiana State University

LSU Digital Commons

Faculty Publications

Department of Biological Sciences

$10-12-2004$

\title{
Studies of fluxes of dissolved iron and manganese in the Gulf of Finland
}

S. V. Pakhomova

P.P.Shirshov Institute of Oceanology, Russian Academy of Sciences

M. Yu Kononets

P.P.Shirshov Institute of Oceanology, Russian Academy of Sciences

A. Tengberg

Göteborgs Universitet

P. O.J. Hall

Göteborgs Universitet

A. V. Vershinin

P.P.Shirshov Institute of Oceanology, Russian Academy of Sciences

Follow this and additional works at: https://digitalcommons.Isu.edu/biosci_pubs

\section{Recommended Citation}

Pakhomova, S., Kononets, M., Tengberg, A., Hall, P., \& Vershinin, A. (2004). Studies of fluxes of dissolved iron and manganese in the Gulf of Finland. USA-Baltic International Symposium: https://doi.org/10.1109/ BALTIC.2004.7296825

This Conference Proceeding is brought to you for free and open access by the Department of Biological Sciences at LSU Digital Commons. It has been accepted for inclusion in Faculty Publications by an authorized administrator of LSU Digital Commons. For more information, please contact ir@lsu.edu. 


\title{
STUDIES OF FLUXES OF DISSOLVED IRON AND MANGANESE IN THE GULF OF FINLAND
}

\author{
S. V. Pakhomova ${ }^{1}$, M. Yu. Kononets ${ }^{1}$, A. Tengberg ${ }^{2}$, P. O.J. Hall ${ }^{2}$ and A. V. Vershinin ${ }^{1}$ \\ ${ }^{1}$ P.P. Shirshov Institute of Oceanology, Russian Academy of Sciences, Nakhimovskii prospekt, 36, \\ 117997 Moscow, Russia \\ ${ }^{2}$ Department of Chemistry, Göteborg University SE-412 96 Göteborg, Sweden \\ E-mail: s-pakhomova@yandex.ru
}

\begin{abstract}
Metal fluxes (total dissolved iron and manganese) across the water-sediment interface were studied in situ in the Gulf of Finland in June 2002 and 2003 using an autonomous benthic lander. Distribution of these metals in the sediment and the porewater was also investigated. Focus was given to understand the behavior of the studied metals at various redox conditions and the influence when sediment resuspension is occurring. Our data indicate the importance of the redox conditions for the iron fluxes with no fluxes at oxic, intermediate at anoxic and high fluxes at suboxic conditions. The fluxes of manganese do not seem to have any correlation with the oxygen levels. Both metals were significantly affected by resuspension, which led to a rapid release.
\end{abstract}

Keywords: the Gulf of Finland, benthic fluxes, manganese, iron, resuspension

\section{Introduction}

The Gulf of Finland is known to be the most eutrophicated sub-basin of the Baltic Sea (Tamsalu and Ennet, 1995; Kuusisto, 1998). Even if the external load of nutrients had decreased in the past decade, the overall situation did not improve, which is attributed to an internal load effect. Its main reason is thought to be accumulation of nutrients in the sediments, which can be released later (e.g. at resuspension or anoxia). Parallel with studies of the turnover of organic material and nutrients at the sediment-water interface we have studied the behavior of metals (i.e. Iron and Manganese). These metals are actively participating in various biogeochemical processes, and they may become additional indicators of environmental conditions and changes in water and sediments.

The aim of this work was to study benthic fluxes of iron and manganese under various redox conditions and under the influence of sediment resuspension. This work is part of a larger ongoing EU-INTAS project named "The importance of sediments for the water quality of the Gulf of Finland".

\section{Materials and Methods}

Studies were carried out in the Gulf of Finland in June 2002 and 2003 (Fig. 1) during two R/V Skagerak cruises. Three stations, two anoxic GF1 and GF2 (in the center of the Gulf) and one oxic GF5 (near Hanko) were studied in 2002. In 2003 metal fluxes were measured at two stations: the oxic (Kasuuni south of Helsinki) and the suboxic (PV1 south of Hanko). At each station both in-situ incubations using an autonomous lander and sediment sampling were performed. Sediment cores $(\mathrm{d}=10 \mathrm{~cm})$, collected with a multicorer, were sliced into $\mathrm{cm}$ intervals to obtain a sediment solid phase and porewater distribution of metals from the same sites as the lander was deployed. Porewater was separated from the sediment using a centrifuge $(2200 \mathrm{rpm}, 30 \mathrm{~min})$ and filtered through $0.45-\mu \mathrm{m}$ cellulose acetate filters.

Benthic fluxes were measured in-situ using the Göteborg benthic lander (Tengberg et al., 2003) which carried four squared acid washed incubation chambers, each capable of closing off an area of 400 $\mathrm{cm}^{2}$ of the sea floor. A "Mississippi-type" paddle wheel (Tengberg et al., 2004) stirred the overlying water in the chambers. In 2002 the stirring speed was constant (100 RPM) during all incubations and no resuspension was induced.

In 2003 the stirring was increased (to 300 RPM) half way through a deployment so that resuspension was created. The degree of resuspension was monitored at 1-minute intervals with turbidity sensors. The concentration of oxygen in each chamber was measured using oxygen optodes. All sensors used were supplied by Aanderaa Instruments Norway (http://www.aanderaa.no). During the incubations a series of 10 discrete water samples were withdrawn at pre-set times into $60-\mathrm{ml}$ acid washed polypropylene syringes from each chamber. Incubations lasted between $15-30$ hours. Bottom water was sampled at the end of an incubation with a "Niskin bottle" mounted on the lander. After lander retrieval the water samples were filtered through disposable $0.45-\mu \mathrm{m}$ cellulose acetate filters. 


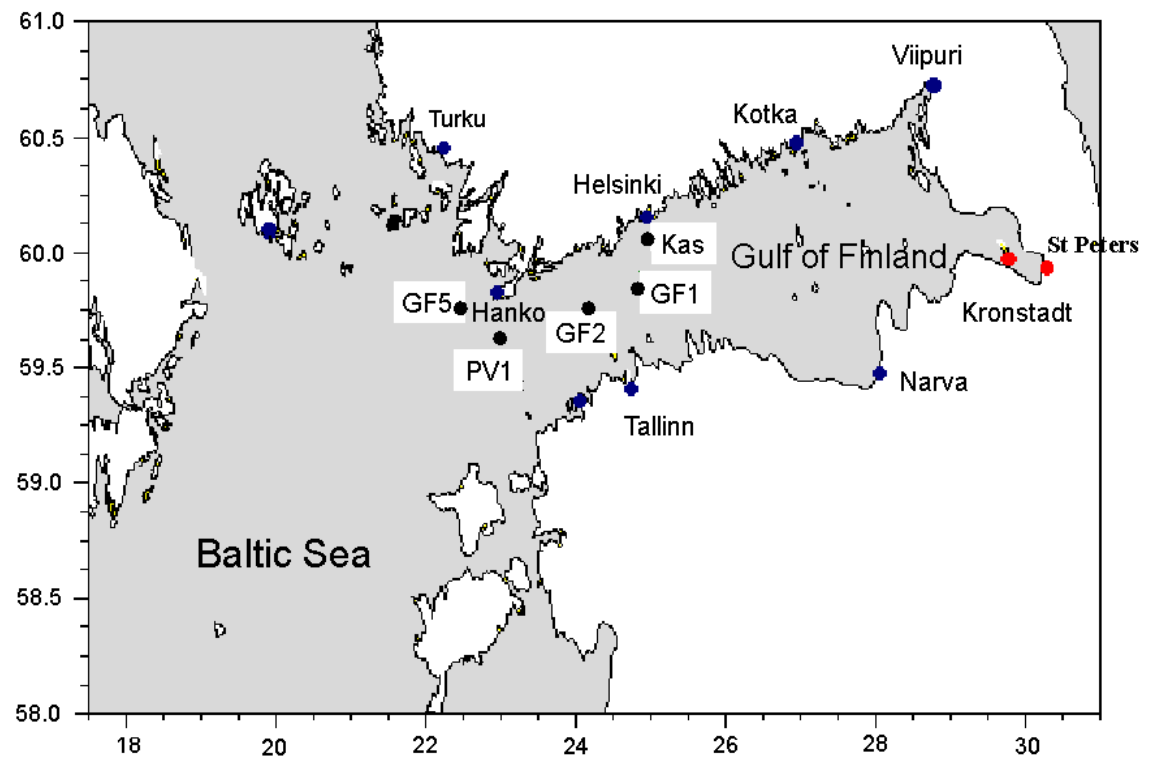

Fig. 1. Map of study sites

Dissolved iron and manganese concentrations were analyzed photometrically using ferrozine and formaldoxyme procedures respectively (Kononets et al., 2002; Marchenko, 1971). Analyses of sediments were carried out using their wet acidic dissolution followed by atomic-absorption metal determination. Concentration of oxygen in bottom water was measured with optodes and with standard Winkler titration procedure.

\section{Results and Discussion}

\subsection{Sediment concentrations}

Solid phase concentration of manganese in the top sediment layer at the anoxic stations GF1 and GF2, and at the suboxic station PV1 was at a level $0.02-0.03 \%$ and slightly increased with depth (Fig.

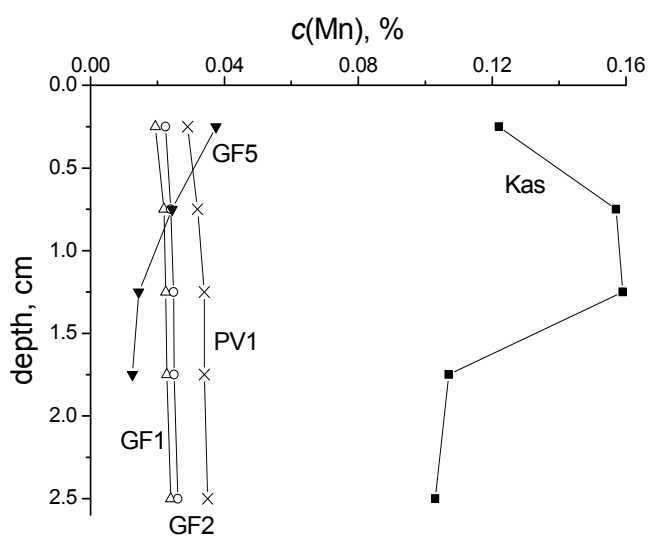

Fig. 2. Distribution of manganese in the sediment solid phase at different stations.
2). At the oxic station GF5 manganese concentration was $0.04 \%$ and decreased with depth. At the oxic station Kasuuni, manganese varied between 0.12 $0.16 \%$.

Iron concentrations in the sediment were fairly constant at a level of $1.5 \%$ for station GF5 (oxic) and about $4 \%$ for all the other stations (Fig. 3). Our data are similar to previous investigations in the area, which have concluded that the distribution of manganese varies in a range of $0.01-0.20 \%$ and tends to increase towards the Russian part of the Gulf. The distribution of iron is practically the same all over the Gulf and falls into a range of $3-5 \%$ (Leivuori, 1998; Vallius, 1999). The low concentration of iron in the solid phase of sediment at the station GF5 is due to the presence of high amounts of sand compared to other stations.

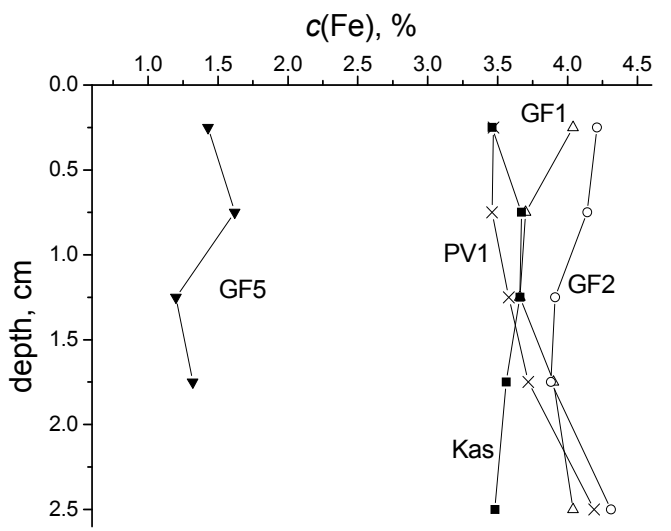

Fig. 3. Distribution of iron in the sediment solid phase at different stations 


\subsection{Porewater concentrations}

Manganese concentration in porewater of the top sediment layer at the anoxic stations GF1 and GF2 was at a level $30 \mu \mathrm{M}$ and slightly increased with depth (Fig. 4). At the suboxic station PV1 the manganese concentration was around three times higher. At both oxic stations GF5 and Kasuuni a subsurface peak was observed at the depth $0.5-1$ $\mathrm{cm}$ and the overall levels were elevated.

Iron concentration in the porewater of the anoxic and suboxic stations decreased with depth from 2.5 to $0.5 \mu \mathrm{M}$ (Fig. 5). At the oxic stations GF5 and Kasuuni iron concentration in the top sediment layer was similar, but a maximum was observed at $1-1.5$

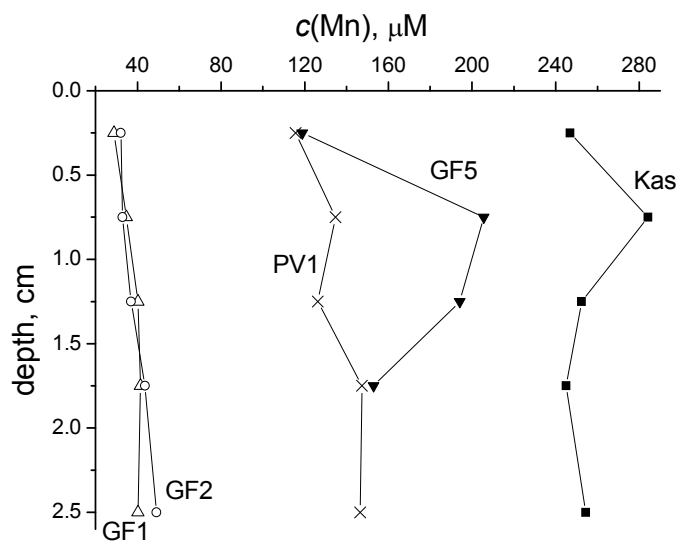

Fig. 4. Distribution of manganese in the porewater at different stations

\subsection{Chamber experiments}

Studies were carried out with a constant-rate stirring in 2002, and in 2003 the influence of resuspension was studied. To do this the stirring rate $\mathrm{cm}$. The peak concentration was as high as $130 \mu \mathrm{M}$ at the GF5 station.

Thus, at the anoxic stations distribution of the $\mathrm{Mn}$ and $\mathrm{Fe}$ in porewater is similar. At the suboxic station (PV1) the iron distribution is similar to the anoxic ones, and the distribution of manganese has the same shape but the absolute concentration is about three times higher. Therefore, one can expect similar Fe and Mn fluxes out from the sediment at GF1 and GF2, and higher for PV1.

At the oxic stations GF5 and Kasuuni the distribution of both metals is similar, but concentrations at the station Kasuuni are higher, which may indicate higher fluxes at this station.

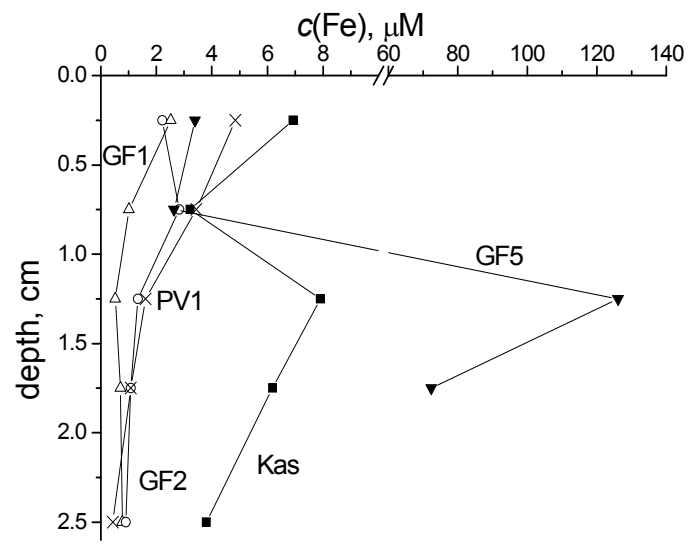

Fig. 5. Distribution of iron in the porewater at different stations

was increased halfway through the incubation, which resulted in a resuspension that was quantified with chamber mounted turbidity sensors.

Table 1

Bottom water concentrations and fluxes of oxygen, iron and manganese

\begin{tabular}{|l|c|c|c|c|c|}
\hline & GF1 & GF2 & GF5 & Kasuuni & PV1 \\
\hline$c\left(\mathrm{O}_{2}\right), \square \mathrm{M}$, bottom water** & 0 & 0 & $340 \pm 0.1 \%$ & $140 \pm 0.4 \%$ & $4 \pm 20 \%$ \\
\hline$J\left(\mathrm{O}_{2}\right), \mathrm{mmol} \mathrm{m}^{-2} \mathrm{~d}^{-1}$ & - & - & $-6.0 \pm 0.1$ & $-8.00 \pm 0.02$ & - \\
\hline$c(\mathrm{Fe}), \square \mathrm{M}$, bottom water** & $1.98 \pm 0.02$ & $1.95 \pm 0.02$ & $0.03 \pm 0.01$ & $0.03 \pm 0.01$ & $0.22 \pm 0.01$ \\
\hline$\Delta c(\mathrm{Fe})_{\mathrm{pw}}, \square \mathrm{M}^{* * *}$ & -11.9 & -3.3 & 1.4 & 6.7 & 4.0 \\
\hline$J(\mathrm{Fe}), \square \mathrm{mol} \mathrm{m}^{-2} \mathrm{~d}^{-1}$ & $9 \pm 1$ & $7 \pm 2$ & $\mathrm{n} / \mathrm{d}$ & $\mathrm{n} / \mathrm{d}$ & $\begin{array}{c}27 \pm 4 \\
(7 \pm 4)^{*}\end{array}$ \\
\hline$c(\mathrm{Mn}), \square \mathrm{M}$, bottom water** & $6.76 \pm 0.07$ & $7.10 \pm 0.07$ & $0.64 \pm 0.01$ & $3.10 \pm 0.02$ & $10.5 \pm 0.1$ \\
\hline$\Delta c(\mathrm{Mn})_{\mathrm{pw}}, \square \mathrm{M}^{* * *}$ & 15.1 & 22.2 & 78.9 & 172.8 & 96.7 \\
\hline$J(\mathrm{Mn}), \square \mathrm{mol} \mathrm{m}^{-2} \mathrm{~d}^{-1}$ & $17 \pm 1$ & $26 \pm 1$ & $30 \pm 1$ & $\begin{array}{c}150 \pm 10 \\
(110 \pm 10)^{*}\end{array}$ & $\begin{array}{c}41 \pm 3 \\
(16 \pm 3)^{*}\end{array}$ \\
\hline
\end{tabular}

*The flux values during resuspension are shown in parentheses

** concentration at $1 \mathrm{~m}$ above the sediment

***difference between the concentration in the porewater of uppermost sediment layer and at $10 \mathrm{~cm}$ above the sediment

\subsection{Manganese fluxes}

The behavior at both anoxic stations GF1 and GF2 was similar (Fig. 6). Manganese concentration increased by $2 \mu \mathrm{M}$, and the increase was linear. At the station PV1 the initial manganese concentration was higher. Before the resuspension the rate of 
increase in the chamber was two times higher compared to the anoxic stations and almost the same as for station GF5. Rapidly after the beginning of resuspension the manganese concentration increased, but its the flux became lower. A likely explanation is that when the top sediment layer was resuspended $\mathrm{Mn}$ was released. The higher concentration in the chamber leads to a lower "flux driving" gradient between the pore- and the chamber water which resulted in a subsequent lower flux.

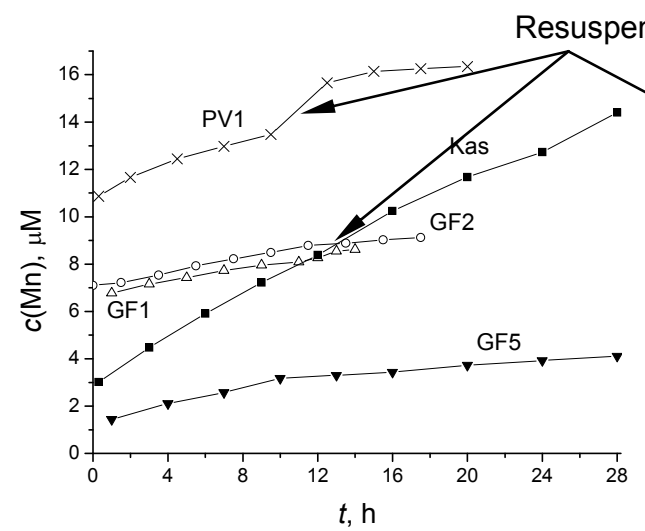

Fig. 6. Release of manganese in chamber
Fig. 7. Release of iron in chamber
At the station Kasuuni the manganese flux was the highest. This can be explained by a high concentration of manganese in the porewater and sediment, which were up to four times higher at this station. After the beginning of resuspension no sudden increase of manganese was observed, but the flux slightly decreased (Table 1). Such decrease of flux could not be attributed to the influence of resuspension only. The increase of the concentration in the chamber experiments is not necessarily linear, and may slow down with time. Similar behavior was observed in previous studies (Pakhomova et al., 2003; Sundby et al., 1986).

It seems that the flux of manganese is mainly governed by its concentration in the porewater and the sediment. This is also supported by the correlation between the flux and the difference between the concentration of manganese in the bottom water and the porewater of the uppermost sediment layer. (Table 1).

\subsection{Iron fluxes}

At the oxic stations GF5 and Kasuuni iron was at the limit of detection and it was not possible to measure any fluxes. At the anoxic stations GF1 and GF2 a small release of iron was observed (Fig. 7). At the station PV1 a significant increase of iron was observed prior to resuspension. After the resuspension was induced the iron concentration rapidly increased by an order of magnitude, but after this the flux was suppressed. The reason is probably the same as for manganese, namely, the involving of the uppermost sediment layers in the exchange, which finally results in a decrease of the flux. But in the case of iron the concentration in chamber water had even exceeded the porewater level. This indicates stronger interaction of sediment into exchange for iron compared to manganese on station PV1.

The difference between the concentration of iron in porewater and in bottom water appeared negative for anoxic stations, and positive for oxic and suboxic stations. But this difference seemed to be only a qualitative characteristic for iron and not really related to the measured fluxes.

The flux of iron depends on the concentration of oxygen in the bottom water. (Skoog et al., 1996; Sundby et al., 1986). As we observed in chamber experiments in the Black Sea on reduced sediments (Pakhomova et al., 2003), when oxygen concentration exceeds $100 \mu \mathrm{M}$, it seems like iron fluxes are absent. When oxygen decreases below $100 \mu \mathrm{M}$ and hydrogen sulfide is absent, an intensive release of iron occurs. Gradually as oxygen is depleted hydrogen sulfide is released and the iron flux is lowered. On station PV1 oxygen did not exceed $20 \mu \mathrm{M}$, consequently, the redox conditions appeared favorable for the release of iron from the sediment, which was observed experimentally (Table 1).

\section{Conclusions}

Fluxes of dissolved manganese and iron were studies at stations with various redox conditions. It was found that the flux of dissolved iron is defined by the concentration of oxygen in the bottom water: under oxic conditions the flux is virtually zero, it is detectable under anoxic conditions and has a maximal value under suboxic conditions. In the case of manganese the direct influence of oxygen was not observed, and the flux of manganese is mainly defined by its concentration in the porewater and the sediment. The influence of resuspension was clearly observed at the station PV1 where it resulted in an 
increase of concentration of both metals and a decrease of fluxes.

More work is needed to gain a better understanding of the mutual influence of metals and other elements, including oxygen and other nutrients, which is planned for the future.

\section{Acknowledgements}

This study was supported by INTAS, project \#2001-0735.

\section{References}

Kononets M. Yu., Pakhomova S. V., Rozanov A. G., Proskurnin M. A., 2002. Determination of soluble iron species in seawater using ferrozine. // Journal of Analytical Chemistry, 57(7): 586 589

Kuusisto M., Koponen J., Sarkkula J., 1998. Modelled phytoplankton dynamics in the Gulf of Finland. // Environmental Modelling and Software, 13: 461 - 470

Leivuori M., 1998. Heavy metal contamination in surface sediments in the Gulf of Finland and comparison with the Gulf of Bothnia. // Chemosphere, 36(1): 43 - 59

Marchenko Z., 1971. Fotometric determination of elements. Moscow, Nauka: 234 - 235. (in Russian)

Pakhomova S. V., Kononets M. Yu., Yudin M. V., Rozanov A. G., 2003. Studies on the fluxes of dissolved forms of iron and manganese through the bottom water-sediment interface on the northeastern shelf of the Black Sea. // Oceanology, 43(4): 493

Skoog A., Hall P., Hulth S., Paxeus N., Rutgers van der Loeff M., Westerlund S., 1996. Early diagenetic production and sediment-water exchange of fluorescent dissolved organic matter in the coastal environment. // Geochimica Cosmochimica Acta 60: 3421 - 3431

Sundby B., Anderson L. G., Hall P. O. J., Iverfeldt A., Rutgers van der Loeff M., Westerlund, S., 1986. The effect of oxygen on release and uptake of cobalt, manganese, iron and phosphate at the sediment-water interface. // Geochimica Cosmochimica Acta, 50(6): 1281 - 1288

Tamsalu R, Ennet P., 1995. Ecosystem modelling in the Gulf of Finland. II. The aquatic ecosystem model FINEST. // Estuarine and Coastal Shelf Science, 41: 429 - 458

Tengberg A., Almroth E., Hall P. O. J., 2003. Resuspension and its effect on organic carbon recycling and nutrient exchange in coastal sediments: In-situ measurements using new experimental technology. // Journal of Experimental Marine Biology and Ecology, 285286: $119-142$

Tengberg, A., Ståhl H., Gust G., Muller V., Arning U., Andersson H., Hall P. O. J., 2004. Intercalibration of benthic flux chambers $\mathrm{I}$. Accuracy of flux measurements and influence of chamber hydrodynamics. // Progress in Oceanography, 60(1): 1 - 28

Vallius H., 1999. Heavy metals deposition and variation in sedimentation rate within a sedimentary basin in central Gulf of Finland. // Chemosphere, 38(9): 1959 - 1972 